\title{
PRODUÇÃO DE BRACHIARIA BRIZANTHA E PANICUM MAXIMUM COM MILHO E ADUBAÇÃO NITROGENADA
}

\author{
PRODUCTION OF BRACHIARIA BRIZANTHA AND PANICUM MAXIMUM WITH CORN \\ AND NITROGEN FERTILIZATION
}

\author{
Barducci, R.S. ${ }^{1 A}$, C. Costa ${ }^{2}$, C.A.C. Crusciol ${ }^{3}$, É. Borghi ${ }^{4}$, T.C. Putarov ${ }^{1 \mathrm{~B}}$ e L.M.N. Sarti ${ }^{1 \mathrm{C}}$
}

${ }^{1}$ Nutrição Animal. Faculdade de Medicina Veterinária e Zootecnia. FMVZ/UNESP. Distrito de Rubião Júnior s/n. CP 560. CEP 18618-000 Botucatu-SP. Brasil. Arobsonbarducci@yahoo.com.br; Bthaputarov@yahoo.com.br; CImsarti@hotmail.com

²Departamento de Melhoramento e Nutrição Animal. FMVZ/UNESP-Botucatu. São Paulo. Brasil. ciniro@fca.unesp.br

${ }^{3}$ Departamento de Produção Vegetal. Agricultura. FCA/UNESP-Botucatu. São Paulo. Brasil. crusciol@fca.unesp.br

${ }^{4}$ Nutrição e Produção Animal. FMVZ/UNESP-Botucatu. São Paulo. Brasil. borghi@fca.unesp.br

\section{PALAVRAS CHAVES ADICIONAIS}

Integração agricultura-pecuária. Milho. Plantio direto. Forrageiras.

\section{RESUMO}

Em regiões caracterizadas com temperaturas altas e ocorrência de chuvas em grande intensidade no verão, porém com inverno seco, as maiores limitações para a sustentabilidade do plantio direto são a baixa produção de palha no período de outono-primavera, aliada a rápida decomposição durante a estação das chuvas. Para tentar solucionar o problema, o cultivo consorciado de culturas produtoras de grãos com espécies forrageiras tem apresentado resultados promissores, dando sustentabilidade ao plantio direto, podendo fornecer forragem no período de maior escassez nas regiões caracterizadas com inverno seco. Contudo, por ser uma tecnologia recente, há necessidade de estudos nas várias áreas abrangidas por esse sistema de produção. Em função do exposto, o projeto de pesquisa teve o seguinte objetivo: 1) avaliar a produção da cultura de milho em diferentes épocas de consorciação com Brachiaria brizantha e Panicum maximum em plantio direto, e 2) o desempenho das forrageiras consorciadas em diferentes épocas e a resposta à adubação nitrogenada aplicada após a colheita do milho, quanto à produtividade de massa e qualidade bromatológica. $O$ experimento foi instalado na Fazenda Experimental Lageado,

Recibido: 7-8-07. Aceptado: 17-1-08.

\section{AdDitiOnAL KEYWORDS}

Agriculture-pasture integration. No tillage systems. Forage.

da Faculdade de Ciências Agronômicas - Campus de Botucatu, em Nitossolo Vermelho Estruturado. O delineamento experimental foi o de blocos casualizados, com quatro repetições. Os tratamentos foram compostos por quatro sistemas de cultivo do milho: 1) cultivo do milho solteiro; 2) cultivo do milho com Brachiaria brizantha cv. Marandu, consorciada na semeadura; 3) cultivo do milho com Brachiaria brizantha cv. Marandu consorciada na adubação de cobertura; 4) cultivo do milho com Panicum maximum cv. Mombaça consorciado na semeadura e 5) cultivo do milho com Panicum maximum cv. Mombaça consorciado na adubação de cobertura. Após a colheita do milho, foi aplicado nitrato de amônio em cobertura nas quantidades equivalentes em nitrogênio $(\mathrm{N})$ nas doses de 0, 30, 60 e $120 \mathrm{~kg} \mathrm{ha}^{-1}$, determinando a produtividade de massa das forrageiras e qualidade bromatológica. O cultivo simultâneo de milho com P. maximum cv. Mombaça na semeadura compromete a produtividade de grãos. Quando semeada em consórcio, a $B$. brizantha apresenta redução no teor de fibra e maior teor de NDT com o decorrer do período de outono-inverno. Tendo em vista os benefícios do cultivo consorciado visando à utilização em sistemas de produção 
como é o caso da integração agricultura-pecuária, o melhor consórcio a ser utilizado é o milho cultivado simultaneamente com $B$. brizantha $\mathrm{cv}$. Marandu.

\section{SUMMARY}

In places characterized with high temperatures and rain occurrence in great intensity in the summer, but with dry winter, the major limitations for the sustainability of no tillage systems are low production of straw during fall-spring period and the fast decomposition during the rain season. To try to solve the problem, intercropped cultures of grains with forage species has presented reliable results; because offer vegetal covering to the next sowing, giving sustainability to the no tillage system. However, being a recent technology, its needed further studies in different areas involved for this system of production. Thus, this study had the objective 1) to evaluate the production of corn grain at different periods of intercropping with Brachiaria brizantha and Panicum maximum in no tillage system, and 2) aimed to evaluate the performance of forage at different periods of intercropping and the responses to nitrogen fertilization after the harvest of the corn, assessing mass productivity and quality. The experiment was carried out at the Lageado experimental farm, School of Agricultural Sciences, Botucatu campus belonged to São Paulo State University (UNESP) in structuralized Red Nitosol (Afisol). The experimental design was randomized blocks with four replications. The treatments were composed for four systems of no tillage involving corn: 1) single corn; 2) corn with Brachiaria brizantha cv. Marandu intercropped in the sowing; 3) corn with Brachiaria brizantha cv. Marandu intercropped with the fertilization of covering; 4) corn with Panicum maximum cv. Mombaça intercropped in the sowing and 5) corn with Panicum maximum cv. Mombaça intercropped with the fertilization of covering. After the harvest of the corn, it was applied, in equivalent quantities of nitrogen, ammonium nitrate in covering in doses of $0,30,60$ and $120 \mathrm{~kg} \mathrm{ha}^{-1}$, determining the forage mass productivity and quality. The simultaneous tillage of corn with $P$. maximum cv. Mombaça in the sowing compromises the grain productivity. When sowed in intercropping, $B$. brizantha presents a fiber concentration reduction and greater TDN concentration during the fall-spring period. Regarding benefits of intercropped cultures seeking to use in systems of production like agriculture-pasture integration, the best intercropping to be utilized is corn sown simultaneously with $B$. brizantha $\mathrm{cv}$. Marandu.

\section{INTRODUÇÃO}

O sistema plantio direto é o grande responsável pelo significativo aumento da produtividade e a continuidade da exploração agrícola dos solos brasileiros. Para a implantação e condução do sistema de maneira sustentável, é indispensável a rotação de culturas de forma à proporcionar a manutenção permanente de uma quantidade mínima de massa vegetal na superfície do solo. O efeito positivo dos resíduos vegetais é aumentado conforme seu tempo de permanência. Este tempo é dependente do resíduo, grau de trituração, quantidade, composição química (principalmente a relação $\mathrm{C} / \mathrm{N}$ ) e grau de contato com o solo (Fiorin, 1999).

A proteção da superfície do solo é especialmente importante para a manutenção das propriedades físicas e a atividade de microrganismos que, uma vez constituídos na matéria orgânica, promovem a liberação de determinados elementos contribuindo para a absorção destes nutrientes pelo sistema radicular das plantas. No entanto, a maior limitação para a sustentabilidade do plantio direto na maior parte do Estado de São Paulo e Brasil Central é a baixa produção de palhada no período de outono/inverno e inverno/ primavera, em razão das condições climáticas desfavoráveis, baixa disponibilidade hídrica, caracterizado pelo inverno seco. Assim, muitas áreas nessas regiões, ficam ociosas durante sete meses do ano e com baixa cobertura vegetal, comprometendo a viabilidade e sustentabilidade do plantio direto.

A aplicação deste sistema de produção em regiões com estas características climáticas é respaldada pelo fato de que o Brasil, atualmente, possuir 100 milhões de hectares com pastagens cultivadas, sendo

Archivos de zootecnia vol. 58, núm. 222, p. 212. 
que $80 \%$ apresentam algum grau e $50 \%$ destas estão em estado avançado de degradação. Tal fato reflete na baixa lotação animal por área, onde a média brasileira não ultrapassa 0,4 unidade animal (UA) por hectare por ano, no baixo ganho de peso durante a estação das chuvas e, principalmente, na elevada perda de peso na estação seca, conseqüentemente, toda a atividade apresenta perdas anuais superiores a um bilhão de dólares. Dessa forma, o sistema de cultivo consorciado proporciona aumento da disponibilidade de forragem em plena estação seca, com qualidade suficiente para manutenção nutricional dos rebanhos, podendo até promover ganho de peso, e produção de palhada para o plantio direto, sem a necessidade de semeadura de plantas de cobertura em inverno/primavera.

Deve-se ressaltar que tanto a Brachiaria brizantha como espécies do gênero Panicum, por possuírem sistema radicular vigoroso e profundo, apresentam elevada tolerância à deficiência hídrica e absorção de nutrientes em camadas mais profundas do solo, desenvolvendo-se em condições ambientais em que a maioria das culturas produtoras de grãos e das espécies utilizadas para cobertura do solo, não se desenvolveriam. Contudo, se o sistema é uma boa alternativa para produção de palhada, o potencial de desenvolvimento da forrageira pode ser limitado pela baixa disponibilidade de $\mathrm{N}$ após a colheita da planta produtora de grãos, contando apenas o $\mathrm{N}$ residual proveniente da adubação da cultura antecessora.

Assim, nesse sistema de cultivo consorciado, o estudo da adubação nitrogenada é de suma importância, podendo, ainda, aumentar a produção de forragem e conseqüentemente a produção animal.

Em função do exposto, no projeto de pesquisa objetivou-se: 1) avaliar a produção da cultura de milho em duas épocas de consorciação com Brachiaria brizantha e Panicum maximum em plantio direto, e 2) avaliar o desempenho das forrageiras consorciadas nas duas épocas e a resposta à adubação nitrogenada aplicada após a colheita do milho, quanto à produtividade de massa e qualidade bromatológica.

\section{MATERIAL E MÉTODOS}

O trabalho de pesquisa foi instalado na Fazenda Experimental Lageado, pertencente à Faculdade de Ciências Agronômicas FCA/UNESP - Campus de Botucatu, localizada no município de Botucatu-SP, latitude $22^{\circ} 51^{\prime} \mathrm{S}$, longitude $48^{\circ} 26^{\prime} \mathrm{W}$ Grw e altitude de $786 \mathrm{~m}$. Segundo a classificação climática de Köeppen, o clima predominante na região é do tipo Cfa, caracterizado pelo clima temperado, região constantemente úmida, tendo quatro ou mais meses com temperaturas médias superiores a $10^{\circ} \mathrm{C}$, cuja temperatura do mês mais quente é igual ou superior a $22^{\circ} \mathrm{C}$ (Martins, 2003). O solo da área experimental foi classificado como Nitossolo Vermelho Estruturado (Embrapa, 1999), sendo manejado há 2 anos em sistema de plantio direto, sem irrigação.

O delineamento experimental utilizado foi o de blocos casualizados, com quatro repetições. Os tratamentos foram compostos por cinco sistemas de cultivo do milho: 1) cultivo do milho solteiro; 2) cultivo do milho com Brachiaria brizantha cv. Marandu, consorciada na semeadura; 3 ) cultivo do milho com Brachiaria brizantha cv. Marandu consorciada na adubação de cobertura; 4) cultivo do milho com Panicum maximum cv. Mombaça consorciado na semeadura e 5) cultivo do milho com Panicum maximum cv. Mombaça consorciado na adubação de cobertura. Cada unidade experimental foi constituída por 10 linhas de 40 metros de comprimento, espaçadas em $80 \mathrm{~cm}$, perfazendo uma área total de $320 \mathrm{~m}^{2}$. Para as avaliações foram consideradas as 6 linhas centrais de cada unidade experimental, desprezando $1 \mathrm{~m}$ na extremidade de cada linha de plantas.

No mês de novembro de 2005, antes da semeadura do milho, foi realizada avaliação para quantificação da produção de massa 
seca da cobertura vegetal composta por palhada de milho + vegetação espontânea, milho + Brachiaria brizantha cv. Marandu e milho + Panicum maximum cv. Mombaça. Nesta avaliação, as produtividades de massa seca foram de 2030,4656 e $5290 \mathrm{~kg} \mathrm{ha}^{-1}$, respectivamente. Após a avaliação, a área experimental foi submetida à uniformização mecânica, utilizando-se triturador horizontal.

No dia 08/12/2005 procedeu-se amostragem do solo conforme metodologia proposta por Raij e Quaggio (1983), para a recomendação da adubação de semeadura segundo Raij et al. (1996). No dia 18/12/ 2005 , a rebrota das forrageiras, assim como da vegetação espontânea, foi controlada com dessecação das plantas utilizando herbicida glyphosate, na dose de 1800 gramas do ingrediente ativo ha-1, com volume de aplicação de 250 lha $^{-1}$. Em 20/12/2005, procedeu-se a semeadura do milho utilizando o híbrido Pioneer 30F90, na população de 55000 plantas ha-1. As espécies forrageiras utilizadas foram Brachiaria brizantha cv. Marandu e Panicum maximum cv. Mombaça, nas quantidades de $20 \mathrm{~kg} \mathrm{ha}^{-1}$, com VC= $24 \%$, sendo as densidades preconizadas conforme Kluthcouski et al. (2000).

$\mathrm{Na}$ semeadura da cultura do milho em consórcio (tratamentos 2 e 4) com Brachiaria brizantha e Panicum maximum, utilizouse semeadora. Nos tratamentos 3 e 5 a semeadura foi realizada concomitantemente com a adubação de cobertura (14/01/2006). A adubação mineral de semeadura do milho constou da aplicação de $\mathrm{N}, \mathrm{P}_{2} \mathrm{O}_{5}$ e $\mathrm{K}_{2} \mathrm{O}$ respectivamente, nas doses de 24,84 e $48 \mathrm{~kg}$ ha ${ }^{1}$, correspondendo a $300 \mathrm{~kg} \mathrm{ha}^{-1}$ do fertilizante formulado 08-28-16, seguindo as recomendações de Raij et al. (1996) para a cultura do milho, com base na análise de solo.

Para implantação das forrageiras em consorciação, as sementes foram misturadas ao fertilizante de semeadura, distribuídos na mesma profundidade do adubo e simultaneamente à semeadura da cultura do milho. As profundidades de deposição do fertilizante + semente das forrageiras foram de $8 \mathrm{~cm}$ e $6 \mathrm{~cm}$, respectivamente, para Brachiaria brizantha cv. Marandu e Panicum maximum cv. Mombaça, objetivando o atraso na emergência das forrageiras e reduzir a competição com a cultura do milho.

Em 10/01/2006 efetuou-se o controle da lagarta do cartucho na cultura do milho por meio de aplicação do inseticida Lufenuron, na dosagem de $25 \mathrm{~g}$ i. a. ha ${ }^{-1}$. Simultaneamente a esta operação, realizou-se o controle de plantas daninhas em pós emergência, com adição na calda do herbicida Atrazina, na dose de 11 i. a. ha-1.

Quando a cultura do milho atingiu o estádio de 4 folhas desenvolvidas, procedeu-se a adubação de cobertura com nitrogênio na dose de $150 \mathrm{~kg} \mathrm{ha}^{-1}$, correspondendo a $500 \mathrm{~kg} \mathrm{ha}^{-1}$ do fertilizante nitrato de amônio,conforme as recomendações de Raij et al. (1996). Nas parcelas onde foram realizadas as semeaduras de Brachiaria brizantha e Panicum maximum juntamente com a adubação de cobertura, as sementes das duas forrageiras foram misturadas separadamente ao nitrato de amônio, e colocadas mecanicamente no solo por meio de adubador de discos a $5 \mathrm{~cm}$ de profundidade. Após a adubação de cobertura efetuou-se aplicação de potássio à lanço, na quantidade de $100 \mathrm{~kg} \mathrm{ha}^{-1} \mathrm{de}_{2} \mathrm{O}$, correspondendo a $170 \mathrm{~kg} \mathrm{ha}^{-1}$ do fertilizante cloreto de potássio, seguindo também as recomendações de Raij et al. (1996).

No restante da área experimental procedeu-se a colheita, adotando como referência para a altura da plataforma a inserção da primeira espiga do milho. Após esta operação, todas as unidades experimentais foram submetidas à uniformização de altura das forrageiras com referência de $50 \mathrm{~cm}$ em relação ao do solo.

Para a avaliação referente à produtividade da cultura do milho, as plantas contidas na área útil de cada unidade experimental (2 linhas centrais com $10 \mathrm{~m}$ de comprimento) foram colhidas manualmen- 
te, pesadas e levadas a uma trilhadora mecânica onde, após debulha, procedeu-se a pesagem dos grãos e os valores extrapolados para $\mathrm{kg} \mathrm{ha}^{-1}$ (à base de $13 \%$ de umidade).

$\mathrm{Na}$ adubação nitrogenada de cobertura nas forrageiras, foram aplicadas quatro doses de nitrogênio $\left(0,30,60\right.$ e $\left.120 \mathrm{~kg} \mathrm{ha}^{-1}\right)$, na forma de nitrato de amônio $\left(\mathrm{NH}_{4} \mathrm{NO}_{3}\right)$, distribuídas na entrelinha das forrageiras, no qual as parcelas permaneceram vedadas até as forrageiras atingirem o porte de $50 \mathrm{~cm}$ de altura em relação ao nível do solo. A partir da aplicação das doses de $\mathrm{N}$, o delineamento experimental continuou em blocos casualizados, sendo a combinação dos quatro fatores do delineamento anterior, constituindo as parcelas, e quatro doses de $\mathrm{N}$, constituindo as subparcelas.

Para quantificação da produtividade de massa seca, foram submetidas a manejo de $25 \mathrm{~cm}$. Em seguida procedeu-se a colheita do material utilizando quadrado metálico com $1 \mathrm{~m}^{2}$ de área, efetuando as amostragens em três pontos dentro de cada subparcela. Após esta avaliação, o restante da área foi uniformizada na mesma altura de corte. Em cada uma das amostragens, o material cortado foi pesado e uma amostra colocada em estufa de ventilação forçada de ar a $60^{\circ} \mathrm{C}$ até peso constante. Destas amostras, determinou-se a porcentagem de massa seca contida nas forragens e a produção de massa seca por hectare para cada espécie separadamente. No total, foram efetuadas 3 avaliações para quantificação da produtividade das forrageiras, realizadas em 20/ 07/06, 29/09/06 e 09/11/06. Em cada amostragem para quantificação da produtividade de massa seca, foram separadas subamostras do material colhido. O material foi picado, sendo uma amostra separada e posteriormente moída para a avaliação das características bromatológicas. Foram determinados os teores de fibra em detergente neutro (FDN), fibra em detergente ácido (FDA), proteína bruta $(\mathrm{PB})$, cinzas, conforme metodologia descrita por Silva (1990) e os teores de nutrientes digestíveis totais (NDT) por meio da fórmula sugerida por Undersander et al. (1993). Todas estas determinações bromatológicas foram realizadas no Laboratório de Análise Bromatológica da Faculdade de Medicina Veterinária e Zootecnia-UNESP - Botucatu.

\section{RESULTADOSEDISCUSSÃO}

\section{ProdutividAdE DE GRÃOS DA CULTURA DO MILHO}

Pelos valores referentes à produtividade de grãos da cultura do milho em função da época de consorciação com Brachiaria brizantha e Panicum, pode-se constatar que esta variável foi influenciada pelos sistemas de cultivo, e principalmente pela espécie forrageira, uma vez que o consórcio do milho com Panicum maximum proporcionou as maiores variações, tendo o sistema de cultivo consorciado simultaneamente à semeadura menor produtividade de grãos e na consorciação realizada por ocasião da adubação de cobertura o maior valor. Para o consórcio do milho com $B$. brizantha, os valores de produtividade de grãos foram significativamente intermediários em relação ao cultivo com $P$. maximum.

Por meio dos dados de variação da produtividade constata-se, em relação ao tratamento testemunha, que o maior incremento na produtividade ocorreu no consórcio com $P$. maximum em cobertura, onde à competitividade que pode estar ocorrendo entre a forrageira e a cultura granífera. As condições climáticas favoráveis, aliado ao espaçamento entre linhas, proporcionou rápido estabelecimento $\mathrm{da}$ forrageira, com maior desenvolvimento, limitando a absorção de água, luz e nutrientes, com a redução na produtividade, no caso da semeadura simultânea.

No caso do consórcio da adubação de cobertura, o maior porte da planta de milho faz a arquitetura foliar promova o rápido fechamento da entrelinha, diminuindo, assim, a incidência de luz, dificultando o esta- 
belecimento da forrageira. Além disso, de acordo com Pantano (2003), o consórcio efetuado nesta fase a competitividade é menor porque o milho ultrapassou o período critico de interferência, e a planta já definiu seu potencial de produtividade. Alguns autores verificaram que a produtividade do milho consorciado com $B$. brizantha concomitantemente à semeadura não sofreu redução significativa em relação ao cultivo solteiro, viabilizando este sistema de produção, assim como constatado neste experimento (Borghi, 2004; Kluthcouski et al., 2000).

Outro fator que pode ser destacado é o arranjo espacial, beneficiando a cultura granífera, a forrageira, que se estabelece da formação de poucos perfilhos, com folhas finas e longas, em virtude da competição por radiação solar. Esses resultados são coincidentes aos relatos de Kluthcouski e Aidar (2003) de que esse sistema de cultivo reduziu significativamente a produção de grãos de milho, em virtude da não aplicação de herbicida graminicida em pós-emergência, tendo encontrado, em algumas regiões, decréscimos de até $17 \%$ na produtividade de grãos. Mesmo no sistema de cultivo com $B$. brizantha na semeadura, a ausência de variação na produtividade de grãos demonstra a possibilidade de utilização deste sistema, tanto para produção de grãos como também de fornecimento de forragem.

Pelos resultados obtidos, o consórcio do milho com forrageiras tropicais pode ser efetuado seguindo as características da espécie a ser efetuada. No consórcio do milho com $B$. brizantha, a semeadura pode ser efetuada simultaneamente à semeadura sem comprometimento na produtividade. Já no consórcio com $P$. maximum, os resultados demonstram que o consórcio efetuado na semeadura compromete a produtividade, devendo ser adotadas práticas para amenizar os efeitos da competição existente entre a forrageira e o milho. Alvarenga et al. (2006) sugerem a aplicação de herbicidas pós-emergentes em sub-doses de forma a suprimir o desenvolvimento da forrageira, principalmente no período que maior comprometimento ao desenvolvimento do milho, que se concentra entre os 15 a 45 dias do ciclo da cultura (Pantano, 2003).

\section{Produtividade de MASSA SECA E COMPO- SIÇÃO QUÍMICO-BROMATOLÓGICA DAS FO- RRAGENS DE B. BRIZANTHA E P. MAXIMUM}

$\mathrm{Na}$ tabela I encontram-se os valores de $\mathrm{F}$ e níveis de significância referentes à produtividade de massa seca nas três amostragens e também no somatório das épocas. Verifica-se pelos dados que nas três épocas e no somatório dos valores houve interação significativa para os sistemas de consórcio e doses de $\mathrm{N}$.

Com relação à primeira amostragem, pode-se observar que somente o sistema de cultivo consorciado do milho com braquiária simultaneamente à semeadura houve resposta quadrática em função das doses de $\mathrm{N}$, sendo que nos demais sistemas não houve aumentos significativos na produtividade em função das doses de $\mathrm{N}$ em cobertura. Até a dose de $60 \mathrm{~kg} \mathrm{ha}^{-1}$ de $\mathrm{N}$ houve decréscimo na produtividade de matéria seca da braquiária, porém com 120 $\mathrm{kg} \mathrm{ha}^{-1}$ de $\mathrm{N}$ proporcionou o maior valor. Para o consórcio efetuado concomitantemente à adubação de cobertura o desenvolvimento das espécies foi totalmente diferente. Nos 20 a 50 dias após a colheita da cultura produtora de grãos, ocorre aparente paralisação no crescimento da braquiária, durante a qual poderia estar ocorrendo realocação de fotoassimiliados dos colmos para a formação de novos perfilhos e folhas (Portes et al., 2000), além de um novo sistema radicular, mais volumoso e eficiente na absorção de nutrientes, pois as condições de fertilidade do solo e da adubação de cobertura proporcionaram recuperação da parte aérea da forrageira. Havendo maior perda de folhas e perfilhos por parte do $P$. maximum em relação à braquiária.

$\mathrm{Na}$ segunda amostragem, constata-se que somente no sistema de consórcio do 
Tabela I. Valores de F e nível de significância referentes à produtividade de matéria seca de Brachiaria brizantha $e$ Panicum maximum em função das épocas de consorciação com milho e da adubação nitrogenada em cobertura. ( $F$ values and level of significance related to dry matter productivity of Brachiaria brizantha and Panicum maximum at different periods of intercropping with corn and nitrogen fertilization in covering).

\begin{tabular}{|c|c|c|c|c|}
\hline & Época 1 & Época 2 & Época 3 & Soma \\
\hline \multicolumn{5}{|l|}{ Valores de F } \\
\hline SC & $142,94^{\star *}$ & $120,80^{\star *}$ & $68,11^{* *}$ & $85,16^{\star *}$ \\
\hline Doses de N (N) & $16,41^{* *}$ & $9,63^{* *}$ & $29,89^{* *}$ & $16,53^{* *}$ \\
\hline $\mathrm{SC} \times \mathrm{N}$ & $33,62^{* *}$ & $7,18^{\star *}$ & $48,02^{* *}$ & $37,37^{* *}$ \\
\hline \multicolumn{5}{|c|}{ Valores de F para Dose de $\mathrm{N}$} \\
\hline R.L. & $0,23^{\text {ns }}$ & $3,33^{\text {ns }}$ & $62,98^{* *}$ & $40,89^{* *}$ \\
\hline R.Q. & $47,64^{* *}$ & $0,76^{\star *}$ & $3,14^{\mathrm{ns}}$ & $0,007^{\text {ns }}$ \\
\hline \multicolumn{5}{|c|}{ Milho $+B$. brizantha em cobertura } \\
\hline R.L. & $10,08^{\text {ns }}$ & $0,37^{\text {ns }}$ & $23,97^{\star *}$ & $11,80^{* *}$ \\
\hline R.Q. & $0,004^{\mathrm{ns}}$ & $21,77^{* *}$ & $33,90^{* *}$ & $39,25^{\star *}$ \\
\hline \multicolumn{5}{|c|}{ Milho $+B$. brizantha na semeadura } \\
\hline R.L. & $111,30^{* *}$ & $2,305^{\text {ns }}$ & $0,07^{\text {ns }}$ & $6,17^{* *}$ \\
\hline R.Q. & $63,81^{* *}$ & $2,98^{\text {ns }}$ & $27,68^{\star *}$ & $46,14^{\star *}$ \\
\hline \multicolumn{5}{|c|}{ Milho + P. maximum em cobertura } \\
\hline R.L. & $2,19^{\text {ns }}$ & $2,87^{\text {ns }}$ & $81,83^{* *}$ & $50,16^{\star *}$ \\
\hline R.Q. & $17,70^{\text {ns }}$ & $0,69^{\text {ns }}$ & $83,34^{\star *}$ & $84,55^{\star *}$ \\
\hline \multicolumn{5}{|c|}{ Milho $+P$. maximum na semeadura } \\
\hline R.L. & $4,71^{\mathrm{ns}}$ & $4,97^{\text {ns }}$ & $2,76^{\mathrm{ns}}$ & $0,04^{\mathrm{ns}}$ \\
\hline R.Q. & $2,79^{\text {ns }}$ & $0,95^{\mathrm{ns}}$ & $1,47^{\mathrm{ns}}$ & $9,79^{\text {ns }}$ \\
\hline \multicolumn{5}{|l|}{ CV (\%) } \\
\hline SC & 5,58 & 4,74 & 5,64 & 3,8 \\
\hline $\mathrm{N}$ & 5,13 & 6,61 & 5,86 & 4,01 \\
\hline
\end{tabular}

${ }^{*} \mathrm{p}<0,05 ;{ }^{* *} \mathrm{p}<0,01 ; \mathrm{ns}=$ não significativo; $\mathrm{SC}=$ sistemas de cultivo.

milho com braquiária por ocasião da adubação de cobertura houve resposta das doses de $\mathrm{N}$ em cobertura, proporcionando acréscimo na produtividade de massa seca até a dose de $64 \mathrm{~kg} \mathrm{ha}^{-1}$ de $\mathrm{N}$, com decréscimo no valor com a maior dose de N. Resultado pode ser atribuído ao fato de que esta espécie foi a que mais sofreu com a competição com o milho quando semeada em cobertura. Assim, a braquiária demorou um tempo maior de recuperação em relação ao consórcio efetuado simultaneamente à semeadura, porém necessitou de um aporte menor de $\mathrm{N}$ para atingir a maior produtividade.

Na última época de avaliação, constatase que somente o consórcio do milho $\operatorname{com} P$. maximum na semeadura não houve resposta na produtividade de massa seca com o incremento das doses de N. Os cultivos efetuados por ocasião da adubação de cobertura apresentaram comportamento semelhante com o incremento nas doses de $\mathrm{N}$, muito embora se observe que, na maior dose, a produtividade foi superior com o $P$. maximum. Além disso constata-se nestes tratamentos que em ambas as espécies houve diminuição na produtividade até a dose de $60 \mathrm{~kg} \mathrm{ha}^{-1}$. O que pode estar ocorrendo é que, para proporcionar acúmulo de massa seca, as forrageiras podem requerer doses muito superiores às utilizadas. $O$ consórcio da braquiária simultaneamente na semeadura apresentou comportamento inverso aos demais sistemas de cultivo, 
diminuindo a produtividade de matéria seca a partir de $61 \mathrm{~kg} \mathrm{ha}^{-1}$ de $\mathrm{N}$.

Somando as épocas verifica-se que somente o cultivo do $P$. maximum quando semeado simultaneamente com o milho há ausência de resposta com o incremento das doses de N. Nos demais sistemas, o comportamento é semelhante à terceira época de amostragem. Com os consórcios efetuados na adubação de cobertura, na maior dose de $\mathrm{N}$ há uma diferença de apenas $214 \mathrm{~kg} \mathrm{ha}^{-1}$ entre as espécies estudadas, sendo o maior valor proporcionado pelo $P$. maximum. Estes resultados evidenciam o fato de que, no caso do consórcio efetuado na adubação de cobertura, a expressão do máximo potencial produtivo das forrageiras somente ocorre na retomada dos fatores limitantes ao seu desenvolvimento. Já no caso do $P$. maximum, as condições predominantes não proporcionaram para a planta se desenvolver, mesmo com o incremento de $\mathrm{N}$ via fertilização, o que pode ser atribuído ao acúmulo de graus-dia necessários para o desenvolvimento. P. maximum semeado em cobertura, a planta apresentava porte bem menor quando comparado ao consórcio na semeadura. Com isso, o estabelecimento das plantas, culminou com resposta bem mais lenta quando comparado com a braquiária. Alvim et al. (1993) observaram que a luminosidade e a temperatura são fatores importantes para determinar o acúmulo de matéria seca das plantas forrageiras tropicais ao longo do ano. De acordo com Aidar et al. (2003), em condições de elevada altitude, as variações de temperaturas diurnas e noturnas aliadas ao decréscimo do comprimento do dia no inverno podem comprometer o acúmulo de biomassa pelas forrageiras.

No caso do cultivo simultâneo da braquiária com o milho, a diferença no acréscimo da produtividade com as épocas de amostragem, pode estar relacionado ao fato de que possa estar havendo maior disponibilidade de $\mathrm{N}$ via mineralização da matéria orgânica quando depositada na superfície do solo por ocasião dos manejos efetuados e da cobertura morta já presente na área.

Na tabela II encontra-se aos valores de F e níveis de significância para as variáveis matéria seca (MS), fibra em detergente neutro (FDN), fibra em detergente ácido (FDA), nutrientes digestíveis totais (NDT), cinzas e proteína bruta $(\mathrm{PB})$ referentes à primeira época de avaliação (julho), constatam-se que em cada variável analisada houve comportamento diferenciado entre os sistemas de cultivo empregados. O cultivo do $P$. maximum proporcionou maior teor de massa seca quando comparado com a $B$. brizantha, sendo que no caso da consorciação efetuada por ocasião da adubação de cobertura a resposta ocorreu de forma linear ao incremento das doses de $\mathrm{N}$ em cobertura. Já na consorciação simultânea com o milho na semeadura o $P$. maximum houve uma diminuição no teor de matéria seca até a dose de $60 \mathrm{~kg} \mathrm{ha}^{-1} \mathrm{de} \mathrm{N}$, porém, na maior dose houve aumento significativo nos valores. Sugerindo a hipótese de que pode ser devido ao grande acúmulo de matéria seca que ainda permaneceu após o manejo mecânico realizado após a colheita de grãos, porém com touceiras bem desenvolvidas, implica, fisiologicamente, encontra em estádio de desenvolvimento avançado e que, para que pudesse ocorrer aumento significativo de produção de massa seca, as doses de $\mathrm{N}$ deveriam ser superiores as utilizadas. O cultivo da braquiária consorciada com o milho na adubação de cobertura apresentou aumento de produtividade de matéria seca nesta avaliação e acabou diminuindo o teor de FDN.

Os maiores teores de FDA estão concentrados nos sistemas de cultivo consorciado simultaneamente à semeadura, nas duas espécies forrageiras. No caso da braquiária, houve diminuição no teor de FDA até a dose de $60 \mathrm{~kg} \mathrm{ha}^{-1}$, porém, constatou-se incremento na maior dose, o que ser atribuído ao fato de que, nesta quantidade de $\mathrm{N}$, a planta se desenvolve 
Tabela II. Valores de F e nível de significância referentes aos teores de matéria seca (MS), fibra em detergente neutro (FDN) e fibra em detergente ácido (FDA), teores nutrientes digestíveis totais $(N D T)$, cinzas e proteína bruta $(P B)$ das forrageiras, referentes à primeira época de avaliação. ( $\mathrm{F}$ values and level of significance related to dry matter, neutral detergent fiber, acid detergent fiber, total digestible nutrients, ash and crude protein of forages first period of assessment).

\begin{tabular}{|c|c|c|c|c|c|c|}
\hline & MS & FDN & FDA & NDT & CINZAS & PB \\
\hline \multicolumn{7}{|l|}{ Valores de F } \\
\hline SC & $7,88^{* *}$ & $7,75^{\star \star}$ & $11,70^{* *}$ & $11,70^{* *}$ & $22,15^{\star \star}$ & $14,33^{* *}$ \\
\hline Doses de N (N) & $2,46^{\text {ns }}$ & $1,03^{\text {ns }}$ & $0,54^{\text {ns }}$ & $0,5^{\text {ns }}$ & $1,48^{\text {ns }}$ & $2,76^{\text {ns }}$ \\
\hline $\mathrm{SC} \times \mathrm{N}$ & $1,96^{\text {ns }}$ & $2,19^{*}$ & $1,4^{\mathrm{ns}}$ & $1,44^{\text {ns }}$ & $0,48^{\text {ns }}$ & $1,61^{\text {ns }}$ \\
\hline \multicolumn{7}{|c|}{ Valores de $\mathrm{F}$ para dose de $\mathrm{N}$} \\
\hline R. L. & $7,31^{\text {** }}$ & $2,21^{\mathrm{ns}}$ & $0,29^{\text {ns }}$ & $0,29^{\text {ns }}$ & $2,12^{\text {ns }}$ & $4,51^{*}$ \\
\hline R.Q. & $0,06^{\text {ns }}$ & $0,28^{\text {ns }}$ & $1,33^{\text {ns }}$ & $1,33^{\text {ns }}$ & $1,95^{\mathrm{ns}}$ & $2,53^{\text {ns }}$ \\
\hline \multicolumn{7}{|c|}{ Milho $+B$. brizantha em cobertura } \\
\hline R. L. & $0,08^{\text {ns }}$ & $13,62^{* *}$ & $0,27^{\text {ns }}$ & $0,27^{\text {ns }}$ & $0,05^{\mathrm{ns}}$ & $1,00^{\text {ns }}$ \\
\hline R.Q. & $1,48^{\text {ns }}$ & $2,47^{\text {ns }}$ & $1,44^{\mathrm{ns}}$ & $1,45^{\text {ns }}$ & $2,08^{\text {ns }}$ & $5,44^{*}$ \\
\hline \multicolumn{7}{|c|}{ Milho $+B$. brizantha na semeadura } \\
\hline R. L. & $0,16^{\mathrm{ns}}$ & $0,17^{\text {ns }}$ & $0,04^{\mathrm{ns}}$ & $0,04^{\mathrm{ns}}$ & $1,59^{\text {ns }}$ & $0,17^{\text {ns }}$ \\
\hline R.Q. & $0,45^{\text {ns }}$ & $0,11^{\text {ns }}$ & $7,95^{\star *}$ & $7,95^{\star *}$ & $1,67^{\text {ns }}$ & $0,03^{\text {ns }}$ \\
\hline \multicolumn{7}{|c|}{ Milho + P. maximum em cobertura } \\
\hline R. L. & $8,27^{\star \star}$ & $0,32^{\mathrm{ns}}$ & $0,24^{\mathrm{ns}}$ & $0,24^{\text {ns }}$ & $1,65^{\text {ns }}$ & $5,22^{*}$ \\
\hline R.Q. & $0,11^{\mathrm{ns}}$ & $0,82^{\text {ns }}$ & $0,30^{\text {ns }}$ & $0,30^{\text {ns }}$ & $0,17^{\text {ns }}$ & $0,05 \mathrm{~ns}$ \\
\hline \multicolumn{7}{|c|}{ Milho + P. maximum na semeadura } \\
\hline R. L. & $3,37^{\text {ns }}$ & $0,07^{\text {ns }}$ & $3,53^{\text {ns }}$ & $3,54^{\mathrm{ns}}$ & $0,02^{\text {ns }}$ & $6,49^{* *}$ \\
\hline R.Q. & $7,27^{* *}$ & $2,09^{\text {ns }}$ & $0,02^{\text {ns }}$ & $0,02^{\text {ns }}$ & $0,13^{\text {ns }}$ & $0,21^{\mathrm{ns}}$ \\
\hline \multicolumn{7}{|l|}{ CV (\%) } \\
\hline SC & 0,96 & 3,56 & 3,63 & 1,61 & 13,52 & 15,26 \\
\hline $\mathrm{N}$ & 0,79 & 3,93 & 5,57 & 2,47 & 12,27 & 12,26 \\
\hline
\end{tabular}

${ }^{*} \mathrm{p}<0,05 ;{ }^{* *} \mathrm{p}<0,01 ; \mathrm{ns}=$ não significativo; $\mathrm{SC}=$ sistemas de cultivo.

mais intensamente em relação as demais doses aplicadas. A mesma inferência pode ser utilizada para o $P$. maximum, porém, nesta espécie, o efeito torna-se mais pronunciado, uma vez que o aumento nas doses de $\mathrm{N}$ implicou no aumento no teor de FDA linearmente. $\mathrm{O}$ aumento nos teores de FDA implicou na diminuição no teor de NDT, principalmente na dose de $120 \mathrm{~kg} \mathrm{ha}^{-1}$. O aumento teor de PB foi constatado na consorciação efetuada por ocasião da adubação de cobertura, porém, no caso do consórcio da semeadura o $P$. maximum houve aumento linear com o incremento das doses de N. Este resultado pode ser decorrente do efeito diluição. No caso da braquiária semeada em cobertura, o que pode ter ocorrido para a diminuição no teor de $\mathrm{PB}$ a partir da dose de $50 \mathrm{~kg} \mathrm{ha}^{-1}$ pode estar atribuído à translocação de proteínas para a formação de novos perfilhos e folhas. Neste sistema constatou-se menor concentração de FDN.

$\mathrm{Na}$ segunda amostragem, pode-se observar que somente nos cultivos consorciados por ocasião da adubação de cobertura proporcionaram respostas significativas no teor de massa seca das forrageiras. No caso da braquiária, o aumento no teor ocorreu de forma linear com o acréscimo de $\mathrm{N}$ via fertilização e para o $P$. maximum o aumento no teor ocorreu até a dose de $68 \mathrm{~kg}$ 
ha $^{-1}$ de N. Destes resultados pode-se inferir que, apesar da diminuição na quantidade de radiação incidente e da temperatura, as forrageiras culminaram em menor desenvolvimento vegetativo, aumentando a concentração de massa seca.

No caso dos sistemas de cultivo consorciados na semeadura, houve aumento no teor de FDN nas duas espécies forrageiras. Para o P. maximum o aumento foi mais expressivo, ocorrendo de forma linear em relação ao incremento nas doses de N, e na braquiária somente na dose de 120 $\mathrm{kg} \mathrm{ha} \mathrm{h}^{-1}$ houve maior teor de FDN. Isso sugerem que, para o P. maximum, quando comparadas com as plantas estabelecidas sob as menores doses, encontram-se fisiologicamente mais desenvolvidas, desta forma o incremento de fertilizante nitrogenado não aumenta de forma exponencial a produtividade de massa seca e proporciona forragem de melhor qualidade. De acordo com Portes et al. (2000), após o manejo, pode ocorrer grande eliminação das folhas, sobrando grande volume de colmos. A dose de $60 \mathrm{~kg} \mathrm{ha}^{-1}$ de $\mathrm{N}$ implicou nas diferenças para os teores de cinzas em função dos sistemas de cultivo consorciados com braquiária na semeadura e $P$. maximum em cobertura. Com relação ao teor de PB nas forragens, somente no cultivo da braquiária consorciada com milho na semeadura houve resposta significativa em relação aos demais tratamentos. Porém, ressalta-se que na maior dose de $\mathrm{N}$ aplicada em cobertura, o valor de PB foi semelhante ao tratamento com ausência de adubação nitrogenada. $\mathrm{O}$ que pode estar ocorrendo neste caso é que, na ausência de nitrogênio ou mesmo o grande estímulo de produção pelo alto teor de $\mathrm{N}$ disponibilizado, as plantas podem apresentar maior conteúdo de colmos em relação a folhas e bainhas, e como a metodologia de coleta procedeu a amostragem dos $25 \mathrm{~cm}$ superiores do relvado, nesta parte da planta ocorra a maior concentração de proteínas. Nas doses de 30 e $60 \mathrm{~kg} \mathrm{ha}^{-1}$ houve diminuição de $\mathrm{PB}$ porque nas plantas submetidas a estas dosagens apresentamse fisiologicamente menos desenvolvidas em relação às plantas adubadas com $120 \mathrm{~kg}$ $\mathrm{ha}^{-1}$ de N, e neste caso, pode estar ocorrendo translocação de proteínas para as gemas localizadas na touceira.

Decorridos 40 dias do manejo, verificouse que somente os sistemas de cultivo consorciado com $P$. maximum apresentaram respostas significativas nas características bromatológicas. Em relação ao teor de FDN, constata-se que o cultivo da forrageira com o milho por ocasião da adubação de cobertura houve diminuição nos teores com o incremento das doses de N, indicando que, ao optar por realizar a semeadura do $P$. maximum na adubação de cobertura do milho, a pastagem poderá ser utilizada apenas nesta época. No caso do cultivo consorciado do $P$. maximum semeado simultaneamente com o milho houve incremento no teor de PB com as doses de $\mathrm{N}$ em cobertura. Nos dois sistemas de cultivo, os resultados indicam que, como esta avaliação foi realizada no mês de novembro, a retomada das temperaturas altas, culminando com o início do período chuvoso e aumento da intensidade luminosa estimulou novamente o crescimento desta espécie. Pode-se então inferir que o cultivo consorciado do milho utilizando $P$. maximum para o período de outono-inverno deve ser melhor avaliado visando os objetivos propostos, que é de fornecer forragem na época de maior escassez de alimento e ainda proporcionar cobertura morta para o sistema plantio direto.

Quando consorciada com o milho na semeadura, além de diminuir a produtividade de grãos, o $P$. maximum não responde à adubação nitrogenada feita após a colheita, aumentando o teor de fibra e com velocidade de acúmulo de massa bem menor quando comparado à braquiária, pois as condições climáticas não são favoráveis ao desenvolvimento. Somente após o início da primavera, onde ocorre o início de temperaturas mais altas durante o dia e o fotoperíodo 


\section{PRODUÇÃO DE FORRAGEIRAS COM MILHO E ADUBAÇÃO NITROGENADA}

começa a aumentar, que a planta inicia seu pleno desenvolvimento. Porém, caso o agricultor tenha necessidade de ter uma pastagem de rápida formação para o início do período de outono esta espécie seria a mais indicada para ser consorciada com o milho, principalmente quando semeada simultaneamente.

\section{CONCLUSÕES}

Os resultados obtidos mostaram que o cultivo simultâneo de milho com P. maximum cv. Mombaça na semeadura compromete a produtividade de grãos.

Não há resposta do $P$. maximum à adubação nitrogenada em cobertura, quando esta espécie é semeada simultaneamente com o milho. A consorciação do milho com a $B$. brizantha efetuado simultaneamente na semeadura apresenta maior produtividade de massa seca, principalmente quando adubada com $120 \mathrm{~kg} \mathrm{ha}^{-1} \mathrm{de} \mathrm{N}$.

\section{BIBLIOGRAFIA}

Aidar, H., J.A.S. Rodrigues e J. Kluthcouski. 2003. Uso da integração lavoura-pecuária para produção de forragem na entressafra. Em: Kluthcouski, J., Stone, L.F., Aidar, H. Integração Lavoura-Pecuária. $1^{\mathrm{a}}$ ed. Embrapa Arroz e Feijão. Santo Antonio de Goiás. Cap. 8. p. 225-262.

Alvarenga, R.C., T. Cobucci, J. Kluthcouski, F.J. Wruck, J.C. Cruz e M.M. Gontijo Neto. 2006. Cultura do milho na integração lavoura-pecuária. Informe Agropecuário: Cultivo do milho no sistema plantio direto. Belo Horizonte, 27: 106-126.

Alvim, M.J., C.E. Martins, M. de A. Botrel, J.A. Salvati e M.A.M. Jacob. 1993. Efeito da irrigação e da integração entre pastagens de setária e de azevém anual sobre a produção de leite. Pesqui. Agropecu. Bras., 28: 545-554.

Borghi, E. 2004. Integração agricultura-pecuária do milho consorciado com Brachiaria brizantha em sistema de plantio direto. Dissertação (Mestrado em Agronomia/Energia na Agricultura). Faculdade de Ciências Agronômicas. Universidade Estadual Paulista. Botucatu. 102 p.

EMBRAPA. 1999. Sistema brasileiro de classificação dos solos. Embrapa/CNPS. Rio de
A B. brizantha apresenta maior potencial de crescimento em resposta à adubação nitrogenada aplicada após a colheita do milho. Além disso, com o decorrer do período, a exigência por nitrogênio requerida para a formação de novas estruturas vegetativas é menor. Quando semeada em consórcio, a $B$. brizantha apresenta redução no teor de fibra e maior teor de NDT com o decorrer do período de outono-inverno.

Tendo em vista os benefícios do cultivo consorciado visando à utilização em sistemas de produção como é o caso da integração agricultura-pecuária, o melhor consórcio a ser utilizado é o milho cultivado simultaneamente com $B$. brizantha $\mathrm{cv}$. Marandu.Estudos mais profundos necessitam ser conduzidos envolvendo novos cultivares dessas espécies forrageiras em consorciação no plantio direto, para avaliar a produção da cultura de milho em diferentes épocas de cultivo.

Janeiro. 412 p.

Fiorin, J.E. 1999. Plantas recuperadoras da fertilidade do solo. Em: Curso sobre aspectos básicos de fertilidade do solo sob plantio direto, Cruz Alta-RS. Resumos de palestras... Editora Aldeia Norte. Passo Fundo, RS. 92 p.

Kluthcouski, J., T. Cobucci, H. Aidar, L.P. Yokoyama, I.P. de Oliveira, J.L. da S. Costa, J.G. da Silva, L. Vilela, A. de O. Bacellos e C. de U. Magnabosco. 2000. Sistema Santa Fé -Tecnologia Embrapa: integração lavoura-pecuária pelo consórcio de culturas anuais com forrageiras, em áreas de lavoura, nos sistemas direto e convencional. Embrapa Arroz e Feijão. Santo Antonio de Goiás, GO. Circular Técnica 38. 28 p.

Kluthcouski, J. e H. Aidar. 2003. Uso da integração lavoura-pecuária na recuperação de pastagens degradadas. Em: Kluthcouski, J., Stone, L.F., Aidar, H. Integração lavoura-pecuária. $1^{a}$ ed. Embrapa Arroz e Feijão. Santo Antonio de Goiás. cap. 6. p. 185-223.

Martins, D. 2003. Classificação climática de Botucatu - SP. (Divulgação interna do Departamento de Ciências Ambientais. Faculdade de 


\section{BARDUCCI, COSTA, CRUSCIOL, BORGHI, PUTAROV E SARTI}

Ciências Agronômicas).

Pântano, A.C. 2003. Semeadura de braquiária em consorciação com milho em diferentes espaçamentos na integração agriculturapecuária em plantio direto. 60f. Dissertação (Mestrado em Agronomia/Sistemas de Produção). Faculdade de Engenharia. Universidade Estadual Paulista. Ilha Solteira.

Portes, T.A., S.I.C. Carvalho, I.P. Oliveira e J. Kluthcouski. 2000. Análise do crescimento de uma cultivar de braquiária em cultivo solteiro e consorciado com cereais. Pesqui. Agropecu. Bras., 35: 1349-1358.

Raij, B. van e J.A. Quaggio. 1983. Métodos de análise de solo para fins de fertilidade. Boletim Técnico Instituto Agronômico, Campinas, $n^{\circ} 81$. $31 \mathrm{p}$.

Raij, B. van, H. Cantarella, J.A. Quaggio e A.M.C Furlani. 1996. Recomendações de adubação e calagem para o Estado de São Paulo. $2^{\mathrm{a}}$ edição. Instituto Agronômico \& Fundação IAC. Campinas. Boletim Técnico 100. 285 p.

Silva, D.J. 1990. Análise de alimentos: métodos químicos e biológicos. $2^{\mathrm{a}}$ ed. Universidade $\mathrm{Fe}-$ deral de Viçosa. Viçosa. $165 \mathrm{p}$.

Undersander, D., D.R. Mertens and N. Thiex. 1993. Forage analyses procedures. National Forage Testing Association. Omaha. p. 130-131.

Archivos de zootecnia vol. 58, núm. 222, p. 222. 